\title{
Predictors of homelessness among vulnerably housed adults in 3 Canadian cities: a prospective cohort study
}

\author{
Matthew J. To ${ }^{1 *}$, Anita Palepu², Tim Aubry ${ }^{3}$, Rosane Nisenbaum, Evie Gogosis ${ }^{1}$, Anne Gadermann², \\ Rebecca Cherner ${ }^{3}$, Susan Farrell ${ }^{4}$, Vachan Misir ${ }^{1}$ and Stephen W. Hwang ${ }^{1,5}$
}

\begin{abstract}
Background: Homelessness is a major concern in many urban communities across North America. Since vulnerably housed individuals are at risk of experiencing homelessness, it is important to identify predictive factors linked to subsequent homelessness in this population. The objectives of this study were to determine the probability of experiencing homelessness among vulnerably housed adults over three years and factors associated with higher risk of homelessness.

Methods: Vulnerably housed adults were recruited in three Canadian cities. Data on demographic characteristics, chronic health conditions, and drug use problems were collected through structured interviews. Housing history was obtained at baseline and annual follow-up interviews. Generalized estimating equations were used to characterize associations between candidate predictors and subsequent experiences of homelessness during each follow-up year.

Results: Among 561 participants, the prevalence of homelessness was $29.2 \%$ over three years. Male gender (AOR $=1.59,95 \% \mathrm{Cl}: 1.14-2.21)$ and severe drug use problems (AOR $=1.98,95 \% \mathrm{Cl}: 1.22-3.20$ ) were independently associated with experiencing homelessness during the follow-up period. Having $\geq 3$ chronic conditions ( $A O R=0.55$, $95 \% \mathrm{Cl}: 0.33-0.94)$ and reporting higher housing quality ( $\mathrm{AOR}=0.99,95 \% \mathrm{Cl}: 0.97-1.00)$ were protective against homelessness.

Conclusions: Vulnerably housed individuals are at high risk for experiencing homelessness. The study has public health implications, highlighting the need for enhanced access to addiction treatment and improved housing quality for this population.
\end{abstract}

Keywords: Homeless persons, Housing, Urban health, Substance-related disorders, Public health

\section{Background}

Homelessness is a major public health concern in many communities across North America. Recent reports suggest an estimated 650,000 individuals across the United States and Canada are homeless on any given night $[1,2]$. Compared with the general population, homeless individuals have poorer health status and a high prevalence of physical and mental health problems [3-5]. As a result,

\footnotetext{
* Correspondence: mto3@alumni.uwo.ca

${ }^{1}$ Centre for Urban Health Solutions, Li Ka Shing Knowledge Institute, St.

Michael's Hospital, 30 Bond Street, Toronto, ON M5B 1W8, Canada

Full list of author information is available at the end of the article
}

they experience high rates of healthcare utilization, morbidity, and mortality [5].

Numerous studies have examined risk factors for onset of homelessness and identified several risk factor categories such as demographic characteristics, physical and mental health status, substance use, involvement with the criminal justice system, and housing conditions [6-13]. With regards to demographic factors, younger age has been associated with a higher likelihood of becoming homeless and shorter duration of homelessness [6, 7]. Male gender and African American ethnicity have been identified as independent predictors of homelessness $[8,9]$. Obtaining less than a high school education 
has also been associated with homelessness [6, 10], while being a college graduate has been recognized as a protective factor [11]. Having no income, lower income, or financial difficulties are risk factors for homelessness [10, 12, 13]. Unemployment has been associated with homelessness [11], while employment and earned income are predictors of a shorter duration of homelessness [7].

A variety of physical and mental health conditions have been linked to homelessness [4]. Physical health problems and worsening of general health have been associated with homelessness $[6,11,14]$. Mental illness and family history of mental illness have been identified as predictors of homelessness [12, 13]. Specifically, homelessness has been linked to schizophrenia [8], bipolar disorder [8], anxiety disorder [11], post-traumatic stress disorder [11], and personality disorder [15].

Moreover, substance use and addictions are important risk factors for homelessness [8, 13, 16]. Illicit drug use and having an alcohol use disorder are both predictors of homelessness [6, 15]. Previous research has identified crack cocaine use as a risk factor for becoming and remaining homeless [17]. In addition, recent drug injection use is associated with homelessness [14].

Previous research has also linked housing status and housing conditions such as crowding with homelessness [9]. Living in unstable housing is also a predictor of homelessness [12]. Protective factors against homelessness include receipt of subsidized housing and having one's own place [9]. Preliminary research has also found an association between social support and homelessness, suggesting that lower social support is linked to chronic homelessness [18].

Although previous research has identified risk factors for onset of homelessness, few studies have examined risk factors for homelessness among individuals who are vulnerably housed, which has been defined as experiencing prior homelessness or having frequent housing transitions [19]. Emerging research suggests that vulnerably housed individuals have similar health and social outcomes to homeless individuals and are at an increased risk of experiencing homelessness $[9,19]$.

Recent studies have found that a substantial proportion of homeless individuals who obtain housing subsequently experience a recurrence of homelessness [20,21]. In one study of 344 single adults in emergency shelters in New York City who were newly homeless, $24 \%$ of those who obtained housing $(81 \%)$ over an 18 -month period had another episode of homelessness. Recurrent homelessness was more common among those who were initially rehoused with family and those with a high school education [20]. Compared to housed individuals, those experiencing recurrent homelessness were more likely to have a 30-day and lifetime history of alcohol and substance use disorders [20]. Another U.S. study examined predictors of returning to homelessness after attaining housing in a sample of 392 formerly homeless veterans who participated in a trial of case management and rent subsidies, case management only, or standard care [21]. Over the course of a five year period, $44 \%$ of all participants experienced another homeless episode after being housed. Participants who received case management and rent subsidies had significantly longer periods of continuous housing compared with participants in the two other groups [21].

Given that vulnerably housed individuals are at risk of experiencing episodes of homelessness, it is important to identify potentially predictive factors linked to subsequent homelessness in this population. The present paper reports findings from the Health and Housing in Transition (HHiT) study, a prospective cohort study that tracked the health and housing status of homeless and vulnerably housed adults in three major Canadian cities [19]. The objectives of this paper are to examine participants who were vulnerably housed at the baseline interview and determine the probability of experiencing homelessness over a three-year follow-up period and the individual characteristics associated with higher risk of homelessness.

\section{Methods \\ Participants}

Homeless and vulnerably housed persons aged 18 or older who were single (i.e. not living with a partner or dependent child) were recruited in Ottawa, Toronto, and Vancouver from January to December 2009. Homelessness was defined as living within the last seven days at a shelter, public space, vehicle, abandoned building, or someone else's home, and not having a home of one's own. Vulnerably housed was defined as currently living in one's own room or apartment, but having been homeless or had two or more moves in the past twelve months. Full-time students and individuals who were visiting the city for three months or less were excluded.

\section{Recruitment}

The sampling procedure for recruiting homeless participants was based on the design suggested by Ardilly and Le Blanc (2001) [22]. Study participants were recruited at homeless shelters and meal programs. Homeless participants who did not use shelters were recruited at meal programs proportionally to the estimated number of homeless persons that slept on the street in each respective city. Vulnerably housed participants were recruited from randomly selected rooming houses in Ottawa and Toronto, and from Single Room Occupancy (SRO) hotels in Vancouver. Due to difficulties in gaining access to some of these locations, the recruitment 
strategy for vulnerably housed individuals was modified to include meal programs, drop-in centers, and community health centers. Data were collected from participants between January 2009 and February 2013. All study participants provided written informed consent and received $\$ 20 \mathrm{CDN}$ upon interview completion. The Research Ethics Boards at the University of Ottawa; St. Michael's Hospital, Toronto; and the University of British Columbia, Vancouver approved this study.

\section{Survey instrument}

Full details of all survey instruments used in the study have been reported elsewhere [19]. Data on demographic characteristics, health conditions and health status, alcohol and drug use, housing history and quality, social support, legal incidents, and victimization were collected using structured, in-person interviews conducted by trained research personnel immediately following recruitment. Interviews took approximately 60 to $90 \mathrm{mi}-$ nutes to complete. Participants reported their ethnic background based on categories adapted from the Statistics Canada Ethnic Diversity Survey [23].

Chronic health conditions listed in the survey tool were adapted from the Canadian Community Health Survey [24], and participants were asked to report any chronic health conditions that had lasted or were expected to last six months or more and had been diagnosed by a healthcare professional. Lifetime prevalence of mental health diagnoses was determined by selfreport. Lifetime prevalence of traumatic brain injury (TBI) was determined using a question from a previous study on prison inmates [25]. Participants were asked whether they had ever had "an injury to the head which knocked you out or at least left you dazed, confused, or disoriented?" Health status was determined using the 12-item Short Form Health Survey (SF-12) to generate Physical Component Summary (PCS) and Mental Component Summary (MCS) subscale scores [26].

Alcohol use was assessed using the Alcohol Use Disorders Identification Test (AUDIT), with a score of eight or more resulting in a positive screen, with scores of 8-15 indicating hazardous, 16-19 harmful, and 20-40 indicating high levels of risk related to alcohol [27]. Drug use problems experienced by participants were assessed using the 10-item version of the Drug Abuse Screening Test (DAST-10) [28]. Scores of three or higher on the DAST10 resulted in a positive screen, with higher scores indicating moderate (scores 3-5), substantial (scores 6-8), or severe (scores 9-10) drug use problems. The Housing Quality Score was used to determine self-reported quality of the current living environment in 6 domains: comfort, safety, spaciousness, privacy, friendliness, and overall quality [29]. Each item was ranked on a 7-point Likert scale with a maximum total score of 42 . Social support was assessed using the Social Support Network Inventory (SSNI), a questionnaire that measured the size of a person's social network and perceived social support [30].

Housing history data were categorized based on methods adapted from Tsemberis et al. [31]. Each residence in a participant's housing history was classified into one of 25 types of residence, which were then classified into one of three mutually exclusive residence categories: housed, institution, and homeless. Periods of time spent in institutions were considered periods of being homeless or housed based on a functional classification [31]. Further details are available from the authors upon request.

Participants provided contact information during administration of the baseline survey so that they could be located for follow-up surveys administered approximately one year, two years, and three years after the baseline survey. The follow-up survey included questions of a similar nature to the baseline survey on health status and health conditions, alcohol and drug use, housing status and quality, and social support.

\section{Data analysis}

Vulnerably housed participants originally recruited into the study who did not complete any follow-up interviews were excluded from the analyses. Descriptive statistics were used to summarize all quantitative variables. The percentage of vulnerably housed adults who experienced homelessness anytime over the three-year followup period was calculated. The main outcome of interest was whether a vulnerably housed participant ever experienced homelessness during any of the three one-year periods between the baseline and follow-up 1 interviews, the follow-up 1 and follow-up 2 interviews, and the follow-up 2 and follow-up 3 interviews.

Baseline characteristics were summarized using means, standard deviations, medians, interquartile ranges, and proportions, wherever appropriate. Comparisons between vulnerably housed participants who did and did not experience homelessness during the three-year follow-up period were performed for baseline characteristics. $P$-values were calculated from $t$-test or Wilcoxon rank-sum test for continuous variables. Chi-square test or Fisher's exact test were used for categorical variables.

Various demographic, health, and housing variables were assessed for an association with a higher probability of becoming homeless over a three-year follow-up period. These characteristics included fixed covariates (determined at the baseline interview) and time-varying covariates (determined at baseline, follow-up 1, followup 2 interviews).

The list of candidate predictors of homelessness was developed based on a literature review and consultation with experts. Characteristics assessed for association 
with experiencing homelessness in the follow-up period were city, time interval, and 1) fixed predictors including: age, gender, ethnicity, highest level of education, percentage of time spent homeless two years prior to baseline divided by 10 for ease of interpretation, number of chronic health conditions ( $\geq 3$ versus $<3$ ), history of a mental health diagnosis, history of TBI, and 2) timevarying predictors evaluated at the beginning of each one-year interval including: employment in the past 12 months, total income in the past 12 months, SF-12 PCS, SF-12 MCS, AUDIT risk level, DAST risk level, housing quality score, and social support network size. For example, SF-12 PCS at baseline, follow-up 1, and follow-up 2 interviews was a time-varying predictor for the main outcome of homelessness during the periods between the baseline and follow-up 1 interviews, the follow-up 1 and follow-up 2 interviews, and the followup 2 and follow-up 3 interviews.

Generalized estimating equations (GEE) with the logit link were used to determine the association between predictors and experiencing homelessness, accounting for the correlations between repeated measurements (SAS PROC GENMOD). For fixed predictors, the quasilikelihood information criteria (QIC) were used to find the correlation structure. For time-varying predictors, we applied the Rotnitzky and Jewell approach [32, 33], and chose the correlation structure for which its associated empirical covariance matrix was closer to the model-based covariance matrix. The GEE model was developed in two steps. Step 1 included city, time interval and fixed predictors, which were retained in the model if significantly associated with or clinically relevant for the outcome (Core Model); Step 2 added time-varying predictors to the Core Model, one at a time. Time-varying predictors significantly associated with or clinically relevant for the outcome were retained in the final model. Analyses for the 2-step process were performed using the exchangeable working correlation structure and coding of time as a continuous variable (time interval years $1,2,3)$ because these settings yielded slightly better goodness of fit statistics. All statistical tests were twotailed and statistical significance was set at a $P$-value of 0.05 or less. SAS 9.4 (SAS Institute, Inc., Cary, NC) was used for all analyses.

\section{Results}

Of 594 vulnerably housed individuals interviewed at baseline, 561 (94.4\%) completed at least one of three follow-up interviews and were included in the analyses. Attrition was due to inability to locate participants, refusal to participate, and death. Baseline characteristics for the whole sample and stratified by city are provided in Table 1.
As per design, equal numbers of vulnerably housed participants were recruited in each city $(34 \%, 33 \%$, $33 \%$ in Ottawa, Toronto, and Vancouver, respectively). The mean age was 42.6 (standard deviation [SD] 9.8) years, and the majority of participants were male, White, born in Canada, had completed some high school, not partnered, and currently unemployed. Participants had a median monthly income of $\$ 900 \mathrm{CDN}$ (interquartile range [IQR] 600-1320) with a median percentage of income spent on rent equal to $41.4 \%$ (IQR 25-62 \%).

More than half of vulnerably housed participants (54\%) were living with 3 or more chronic health conditions. Fifty-five percent of participants had ever received a mental health diagnosis and $64 \%$ reported having a prior TBI. Mean SF-12 PCS score was 43.6 (SD 10.79) and mean SF-12 MCS score was 39.93 (SD 13.02). Two hundred and twenty-two (40 \%) participants had a positive AUDIT screen and 322 (58 \%) had a positive DAST screen. Almost all participants had their own place (95.7\%) or stayed in a place belonging to friends or family (4.3\%). Of this group, $85 \%$ had experienced homelessness in the one-year period before entering the study. Median age at first homelessness was 24 (IQR 16-38) and median lifetime years of homelessness was 3.15 (IQR 1-6.73) among participants. Less than half of participants (41\%) were residing in subsidized housing. Mean housing quality score was 27.53 (SD 8.21).

Over the three-year period, 269 of 561 (48 \%) participants experienced at least one episode of homelessness, while 292 (52 \%) never reported homelessness. Among those who had experienced homelessness, the median duration was 202 (IQR 92-456) days. Those who experienced homelessness during the three-year follow-up period were significantly more likely at baseline to have been younger, born in Canada, completed high school/ equivalent, employed in the past 12 months, smoked cigarettes daily, have positive AUDIT and DAST screens, and experienced arrests or incarceration in the past 12 months $(\mathrm{p}<0.05)$ (Table 2).

Across 1618 residential records of the 561 participants, the prevalence of homelessness was $29 \%$. Specifically, the prevalence of homelessness among residential records of participants was $30.7 \%, 28.5 \%$ and $28.3 \%$ between baseline and follow-up at 1 year, between follow-up at 1 year and follow-up at 2 years, between follow-up at 2 years and follow-up at 3 years, respectively. Participants experienced a variety of residential state trajectories, where many individuals experienced transitions into and out of homelessness (Fig. 1).

Table 3 presents GEE results. In the final multivariable model, residing in Ottawa (Adjusted Odds Ratio [AOR] $=1.88,95 \%$ Confidence Interval $[\mathrm{CI}]: 1.31-2.70)$, male gender $(\mathrm{AOR}=1.59,95 \% \mathrm{CI}: 1.14-2.21)$, percentage of time homeless prior to the baseline interview $(\mathrm{AOR}=$ 
Table 1 Baseline characteristics of 561 vulnerably housed adults in 3 Canadian cities

\begin{tabular}{|c|c|c|c|c|}
\hline Characteristic & $\begin{array}{l}\text { Total } \\
(N=561)^{a} \\
n(\%)\end{array}$ & $\begin{array}{l}\text { Ottawa } \\
(N=190)^{a} \\
n(\%)\end{array}$ & $\begin{array}{l}\text { Toronto } \\
(N=186)^{a} \\
n(\%)\end{array}$ & $\begin{array}{l}\text { Vancouver } \\
(N=185)^{\mathrm{a}} \\
\mathrm{n}(\%)\end{array}$ \\
\hline \multicolumn{5}{|l|}{ Age Group } \\
\hline$<30$ years & $63(11.2)$ & $30(15.8)$ & $12(6.5)$ & $21(11.4)$ \\
\hline $30-39$ years & $137(24.4)$ & $50(26.3)$ & $40(21.5)$ & $47(25.4)$ \\
\hline $40-49$ years & $221(39.4)$ & $62(32.6)$ & $87(46.8)$ & $72(38.9)$ \\
\hline$\geq 50$ years & $140(25)$ & $48(25.3)$ & $47(25.3)$ & $45(24.3)$ \\
\hline Mean age (SD) & $42.6(9.8)$ & $41.5(10.5)$ & $43.8(9.4)$ & $42.5(9.4)$ \\
\hline \multicolumn{5}{|l|}{ Gender } \\
\hline Male & $391(69.7)$ & 149 (78.4) & $125(67.2)$ & $117(63.2)$ \\
\hline Female & $162(28.9)$ & 41 (21.6) & $57(30.7)$ & $64(34.6)$ \\
\hline Transgendered & $8(1.4)$ & 0 & $4(2.2)$ & $4(2.2)$ \\
\hline \multicolumn{5}{|l|}{ Ethnicity } \\
\hline White & $344(63.4)$ & $149(79.3)$ & $90(51.1)$ & $105(58.7)$ \\
\hline Black/African-Canadian & $36(6.6)$ & $3(1.6)$ & $27(15.3)$ & $6(3.4)$ \\
\hline First Nations/Aboriginal & $122(22.5)$ & $32(17)$ & $37(21)$ & $53(29.6)$ \\
\hline Mixed/other & $41(7.6)$ & $4(2.1)$ & $22(12.5)$ & $15(8.4)$ \\
\hline Born in Canada & $496(89.4)$ & $183(96.8)$ & $147(79)$ & $166(92.2)$ \\
\hline \multicolumn{5}{|l|}{ Highest level of education } \\
\hline Some high school & $279(50.4)$ & $100(53.2)$ & $86(46.7)$ & $93(51.1)$ \\
\hline Completed high school/equivalent & $121(21.8)$ & $36(19.2)$ & $42(22.8)$ & $43(23.6)$ \\
\hline Some post-secondary or higher & $154(27.8)$ & $52(27.7)$ & $56(30.4)$ & $46(25.3)$ \\
\hline Partnered & $134(24.3)$ & $48(25.7)$ & $37(20.1)$ & $49(27.1)$ \\
\hline Employed in past 12 months & $213(38)$ & $84(44.4)$ & $61(32.8)$ & $68(36.8)$ \\
\hline Monthly income, median (IQR) & $900(600-1320)$ & $912.33(591-1340)$ & $750(550-1200)$ & $966(698-1480)$ \\
\hline Percent of income spent on rent, median (IQR) & $41.4(25.0-62.0)$ & $43.0(27.3-63.6)$ & $38.9(22.8-65.0)$ & $41.1(27.8-57.9)$ \\
\hline \multicolumn{5}{|l|}{ Chronic health conditions } \\
\hline 0 & $55(9.8)$ & $10(5.3)$ & $36(19.4)$ & $9(4.9)$ \\
\hline 1 & $106(18.9)$ & $31(16.3)$ & $38(20.4)$ & $37(20)$ \\
\hline 2 & $97(17.3)$ & $32(16.8)$ & $36(19.4)$ & $29(15.7)$ \\
\hline$\geq 3$ & $303(54)$ & $117(61.6)$ & $76(40.9)$ & $110(59.5)$ \\
\hline History of a mental health diagnosis & $303(54.9)$ & $120(64.9)$ & $78(42.2)$ & $105(57.7)$ \\
\hline History of traumatic brain injury & $358(64)$ & $136(72)$ & $97(52.4)$ & $125(67.6)$ \\
\hline SF-12 PCS, mean (SD) & $43.6(10.8)$ & $43.01(11.3)$ & $44.42(10.26)$ & $43.35(10.8)$ \\
\hline SF-12 MCS, mean (SD) & $39.93(13)$ & $39.04(13.5)$ & $40.77(12.79)$ & $39.97(12.76)$ \\
\hline Pregnancy in past 12 months & $12(7.5)$ & $4(10)$ & $3(5.3)$ & $5(7.8)$ \\
\hline \multicolumn{5}{|l|}{ Currently smoking } \\
\hline Daily & $451(80.8)$ & $161(85.2)$ & $138(74.6)$ & $152(82.6)$ \\
\hline Occasionally & $46(8.2)$ & $11(5.8)$ & $22(11.9)$ & $13(7.1)$ \\
\hline Not at all & $61(10.9)$ & $17(9)$ & $25(13.5)$ & $19(10.3)$ \\
\hline Positive AUDIT screen & $222(39.7)$ & $82(43.4)$ & $76(40.9)$ & $64(34.8)$ \\
\hline
\end{tabular}


Table 1 Baseline characteristics of 561 vulnerably housed adults in 3 Canadian cities (Continued)

\begin{tabular}{|c|c|c|c|c|}
\hline \multicolumn{5}{|l|}{ AUDIT risk } \\
\hline Low & $337(60.3)$ & $107(56.6)$ & $110(59.1)$ & $120(65.2)$ \\
\hline Hazardous & $88(15.7)$ & $31(16.4)$ & $30(16.1)$ & $27(14.7)$ \\
\hline Harmful & $31(5.6)$ & $12(6.4)$ & $11(5.9)$ & $8(4.4)$ \\
\hline High & $103(18.4)$ & 39 (20.6) & $35(18.8)$ & $29(15.8)$ \\
\hline Positive DAST screen & $322(57.6)$ & $109(57.7)$ & $85(45.7)$ & $128(69.6)$ \\
\hline \multicolumn{5}{|l|}{ DAST risk } \\
\hline No drug use in past 12 months & $136(24.3)$ & $35(18.5)$ & $72(38.7)$ & $29(15.8)$ \\
\hline Low & $101(18.1)$ & $45(23.8)$ & $29(15.6)$ & $27(14.7)$ \\
\hline Moderate & $141(25.2)$ & $50(26.5)$ & 34 (18.3) & $57(31)$ \\
\hline Substantial & $134(24)$ & 37 (19.6) & $38(20.4)$ & $59(32.1)$ \\
\hline Severe & $47(8.4)$ & $22(11.6)$ & $13(7)$ & $12(6.5)$ \\
\hline Arrests and/or incarceration in past 12 months & $190(34)$ & $68(36.2)$ & $61(32.8)$ & $61(33)$ \\
\hline Physical assault victim in past 12 months & $206(37)$ & $74(39.6)$ & $63(34.1)$ & $69(37.3)$ \\
\hline Sexual assault victim in past 12 months & $46(8.3)$ & $14(7.5)$ & $11(5.9)$ & $21(11.5)$ \\
\hline Age at first homelessness, median (IQR) & $24(16-38)$ & $22(16-38)$ & $27(16-39)$ & $23(15-38)$ \\
\hline Lifetime years of homelessness, median (IQR) & $3.15(1-6.73)$ & $2.38(0.93-6)$ & $3.5(1-8.56)$ & $3.56(1.38-6.74)$ \\
\hline Own place & $511(95.7)$ & $182(97.3)$ & $155(91.2)$ & $174(98.3)$ \\
\hline Subsidized housing & $213(40.8)$ & $42(23.2)$ & $97(57.1)$ & $74(43.3)$ \\
\hline \multicolumn{5}{|l|}{ Residence Type } \\
\hline Own house, apartment & $180(32.1)$ & $66(34.7)$ & $99(53.2)$ & $15(8.1)$ \\
\hline Stay with friends and/or relatives & $13(2.3)$ & $2(1.1)$ & $9(4.8)$ & $2(1.1)$ \\
\hline Rooming house & $197(35.1)$ & $118(62.1)$ & $75(40.3)$ & $4(2.2)$ \\
\hline SRO & $160(28.5)$ & 0 & 0 & $160(86.5)$ \\
\hline Substance abuse treatment facility & $4(0.7)$ & 0 & 0 & $4(2.2)$ \\
\hline Halfway house & $2(0.4)$ & $2(1.1)$ & 0 & 0 \\
\hline Supportive housing & $1(0.2)$ & $1(0.5)$ & 0 & 0 \\
\hline Alternative housing & $3(0.5)$ & 0 & $3(1.6)$ & 0 \\
\hline Other & $1(0.2)$ & $1(0.5)$ & 0 & 0 \\
\hline Housing quality, mean (SD) & $27.53(8.2)$ & $27.44(8.6)$ & $28.48(8.1)$ & $26.67(7.85)$ \\
\hline \multicolumn{5}{|l|}{ Social support network size } \\
\hline 0 & $95(17.3)$ & $33(17.8)$ & $36(19.4)$ & $26(14.5)$ \\
\hline 1 & $61(11.1)$ & $21(11.4)$ & $16(8.6)$ & $24(13.4)$ \\
\hline $2-3$ & $104(18.9)$ & $29(15.7)$ & $38(20.4)$ & $37(20.7)$ \\
\hline$\geq 4$ & $290(52.7)$ & $102(55.1)$ & 96 (51.6) & 92 (51.4) \\
\hline
\end{tabular}

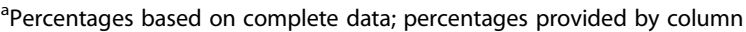

1.06, $95 \%$ CI: 1.01-1.11), moderate DAST risk level $(\mathrm{AOR}=1.4,95 \% \mathrm{CI}: 1.00-1.97)$ substantial DAST risk level (AOR = 1.71, $95 \%$ CI: 1.20-2.44), and severe DAST risk level $(\mathrm{AOR}=1.98,95 \% \mathrm{CI}$ : 1.22-3.20) were independently associated with experiencing homelessness over the three-year follow-up period. Factors that were independently associated with a decreased likelihood of experiencing homelessness over the three-year follow-up period were having less than a high school education (AOR $=0.68,95 \% \mathrm{CI}$ : $0.50-0.91$ ), having 3 or more chronic health conditions (AOR $=0.55,95 \% \mathrm{CI}$ : $0.33-$ $0.94)$, and higher per unit housing quality $(\mathrm{AOR}=0.99$, 95 \% CI: 0.97-1.00).

\section{Discussion}

Among residential records of vulnerably housed participants, the prevalence of homelessness was $29 \%$ over the three-year follow-up period, suggesting that experiences of homelessness are relatively common in this population. This finding is similar to other studies that have 
Table 2 Baseline characteristics for 561 vulnerably housed participants across 3 Canadian cities who did and did not experience homelessness during the 3-year follow-up period

\begin{tabular}{|c|c|c|c|c|}
\hline Characteristic & $\begin{array}{l}\text { Total } \\
(N=561)^{a} \\
\mathrm{n}(\%)\end{array}$ & $\begin{array}{l}\text { Ever homeless } \\
(N=269)^{\mathrm{a}} \\
\mathrm{n}(\%)\end{array}$ & $\begin{array}{l}\text { Never homeless } \\
(N=292)^{a} \\
\mathrm{n}(\%)\end{array}$ & $P$-value \\
\hline Age Group & & & & 0.0226 \\
\hline$<30$ years & $63(11.2)$ & $31(11.5)$ & $32(11.0)$ & \\
\hline 30-39 years & $137(24.4)$ & 77 (28.6) & $60(20.6)$ & \\
\hline 40-49 years & $221(39.4)$ & $108(40.2)$ & $113(38.7)$ & \\
\hline$\geq 50$ years & $140(25)$ & $53(19.7)$ & $87(29.8)$ & \\
\hline Mean age (SD) & $42.6(9.8)$ & $41.3(9.2)$ & $43.8(10.2)$ & 0.0033 \\
\hline Gender & & & & 0.0527 \\
\hline Male & $391(69.7)$ & $65(24.2)$ & $97(33.2)$ & \\
\hline Female & $162(28.9)$ & $200(74.4)$ & $191(65.4)$ & \\
\hline Transgendered & $8(1.4)$ & $4(1.5)$ & $4(1.4)$ & \\
\hline Ethnicity & & & & 0.7361 \\
\hline White & $344(63.4)$ & $167(64.5)$ & $177(62.3)$ & \\
\hline Black/African-Canadian & $36(6.6)$ & $14(5.4)$ & $22(7.8)$ & \\
\hline First Nations/Aboriginal & $122(22.5)$ & $59(22.8)$ & $63(22.2)$ & \\
\hline Mixed/other & $41(7.6)$ & $19(7.3)$ & $22(7.8)$ & \\
\hline Born in Canada & $496(89.4)$ & $246(92.5)$ & $250(86.5)$ & 0.0225 \\
\hline Highest level of education & & & & 0.0009 \\
\hline Some high school & $279(50.4)$ & $119(44.7)$ & $160(55.6)$ & \\
\hline Completed high school/equivalent & $121(21.8)$ & $76(28.6)$ & $45(15.6)$ & \\
\hline Some post-secondary or higher & $154(27.8)$ & $71(26.7)$ & $83(28.8)$ & \\
\hline Partnered & $134(24.3)$ & $64(24.2)$ & $70(24.4)$ & 0.9478 \\
\hline Employed in past 12 months & $213(38.0)$ & $114(42.4)$ & $99(34.0)$ & 0.0418 \\
\hline Monthly income, median (IQR) & $900(600-1320)$ & $920.0(630-1540)$ & $889(586-1200)$ & 0.0906 \\
\hline Percent of income spent on rent, median (IQR) & $41.4(25.0-62.0)$ & $41.0(22.5-62.3)$ & $41.7(27.3-60.9)$ & 0.4403 \\
\hline Chronic health conditions & & & & 0.0609 \\
\hline 0 & $55(9.8)$ & $32(11.9)$ & $23(7.9)$ & \\
\hline 1 & $106(18.9)$ & $52(19.3)$ & $54(18.5)$ & \\
\hline 2 & $97(17.3)$ & $54(20.1)$ & $43(14.7)$ & \\
\hline$\geq 3$ & $303(54)$ & $131(48.7)$ & $172(58.9)$ & \\
\hline History of a mental health diagnosis & $303(54.9)$ & $153(57.3)$ & $150(52.6)$ & 0.2703 \\
\hline History of traumatic brain injury & $358(64)$ & $169(62.8)$ & $189(65.2)$ & 0.5634 \\
\hline SF-12 PCS, mean (SD) & $43.6(10.8)$ & $44.3(11.2)$ & $43.0(10.4)$ & 0.1507 \\
\hline SF-12 MCS, mean (SD) & $39.9(13.0)$ & $40.3(12.4)$ & $39.6(13.6)$ & 0.5231 \\
\hline Pregnancy in past 12 months & $12(7.5)$ & $6(9.2)$ & $6(6.3)$ & 0.4798 \\
\hline Currently smoking & & & & 0.0002 \\
\hline Daily & $451(80.8)$ & $231(86.2)$ & $220(75.9)$ & \\
\hline Occasionally & $46(8.2)$ & $23(8.6)$ & $23(7.9)$ & \\
\hline Not at all & $61(10.9)$ & $14(5.2)$ & $47(16.2)$ & \\
\hline
\end{tabular}


Table 2 Baseline characteristics for 561 vulnerably housed participants across 3 Canadian cities who did and did not experience homelessness during the 3-year follow-up period (Continued)

\begin{tabular}{|c|c|c|c|c|}
\hline Positive AUDIT screen & $222(39.7)$ & $119(44.2)$ & $103(35.5)$ & 0.0353 \\
\hline AUDIT risk & & & & 0.1388 \\
\hline Low & $337(60.3)$ & $150(55.8)$ & $187(64.5)$ & \\
\hline Hazardous & $88(15.7)$ & $44(16.4)$ & $44(15.2)$ & \\
\hline Harmful & $31(5.6)$ & $16(6.0)$ & $15(5.2)$ & \\
\hline High & $103(18.4)$ & $59(21.9)$ & $44(15.2)$ & \\
\hline Positive DAST screen & $322(57.6)$ & $169(62.8)$ & $153(52.8)$ & 0.0161 \\
\hline DAST risk & & & & 0.0994 \\
\hline No drug use in past 12 months & $136(24.3)$ & $57(21.2)$ & $79(27.2)$ & \\
\hline Low & $101(18.1)$ & $43(16.0)$ & $58(20.0)$ & \\
\hline Moderate & $141(25.2)$ & $68(25.3)$ & $73(25.2)$ & \\
\hline Substantial & $134(24)$ & $76(28.3)$ & $58(20.0)$ & \\
\hline Severe & $47(8.4)$ & $25(9.3)$ & $22(7.6)$ & \\
\hline Arrests and/or incarceration in past 12 months & $190(34)$ & $108(40.3)$ & $82(28.2)$ & 0.0025 \\
\hline Physical assault victim in past 12 months & $206(37)$ & $99(37.1)$ & $107(36.9)$ & 0.9645 \\
\hline Sexual assault victim in past 12 months & $46(8.3)$ & $26(9.7)$ & $20(6.9)$ & 0.2335 \\
\hline Age at first homelessness, median (IQR) & $24(16-38)$ & $22.0(16-36)$ & $25(16-40)$ & 0.1910 \\
\hline Lifetime years of homelessness, median (IQR) & $3.2(1.0-6.7)$ & $3.0(1.0-6.7)$ & $3.3(1.0-6.7)$ & 0.6692 \\
\hline Own place & $511(95.7)$ & $240(94.5)$ & $271(96.8)$ & 0.1915 \\
\hline Subsidized housing & $213(40.8)$ & $91(36.6)$ & $122(44.7)$ & 0.0587 \\
\hline Residence Type & & & & 0.2207 \\
\hline Own house, apartment & $180(32.1)$ & $89(33.1)$ & $91(31.2)$ & \\
\hline Stay with friends and/or relatives & $13(2.3)$ & $8(3.0)$ & $5(1.7)$ & \\
\hline Rooming house/SRO & $357(63.6)$ & $164(61.0)$ & $193(66.1)$ & \\
\hline Institution/Other & $11(2.0)$ & $8(3.0)$ & $3(1.0)$ & \\
\hline Housing quality, mean (SD) & $27.53(8.2)$ & $27.4(8.2)$ & $27.7(8.2)$ & 0.6849 \\
\hline Social support network size & & & & 0.3289 \\
\hline 0 & $95(17.3)$ & $45(17.0)$ & $50(17.5)$ & \\
\hline 1 & $61(11.1)$ & $23(8.7)$ & $38(13.3)$ & \\
\hline $2-3$ & $104(18.9)$ & $50(18.9)$ & $54(19.0)$ & \\
\hline$\geq 4$ & $290(52.7)$ & 147 (55.5) & $143(50.2)$ & \\
\hline
\end{tabular}

Percentages based on complete data; percentages provided by column

${ }^{\mathrm{b}} P$-value calculated from $t$-test or Wilcoxon rank-sum test for continuous variables, chi-square test or Fisher's exact test for categorical variables

found that $24-44 \%$ of individuals with prior homeless episodes experienced a recurrence of homelessness [20, 21]. The current study also revealed a variety of housing trajectories among participants, with many individuals experiencing multiple episodes of homelessness and being housed over the follow-up period. These findings suggest that vulnerably housed individuals frequently experience housing instability and housing transitions, similar to what has been previously reported for homeless individuals [19].

The study also identified several risk factors of subsequent homelessness. Vulnerably housed individuals who were male, residing in Ottawa, had spent a higher percentage of time homeless prior to the baseline interview, or had moderate to severe drug use problems were significantly more likely to experience homelessness over the three-year follow-up period despite adjustment for potential confounders.

Gender was a significant predictor of homelessness among vulnerably housed individuals, with men being 1.6 times more likely to experience homelessness compared to women during the follow-up period. This is consistent with previous research that has identified male gender as a risk factor for homelessness [8]. Ottawa participants were also more likely to experience homelessness during the follow-up period compared to 


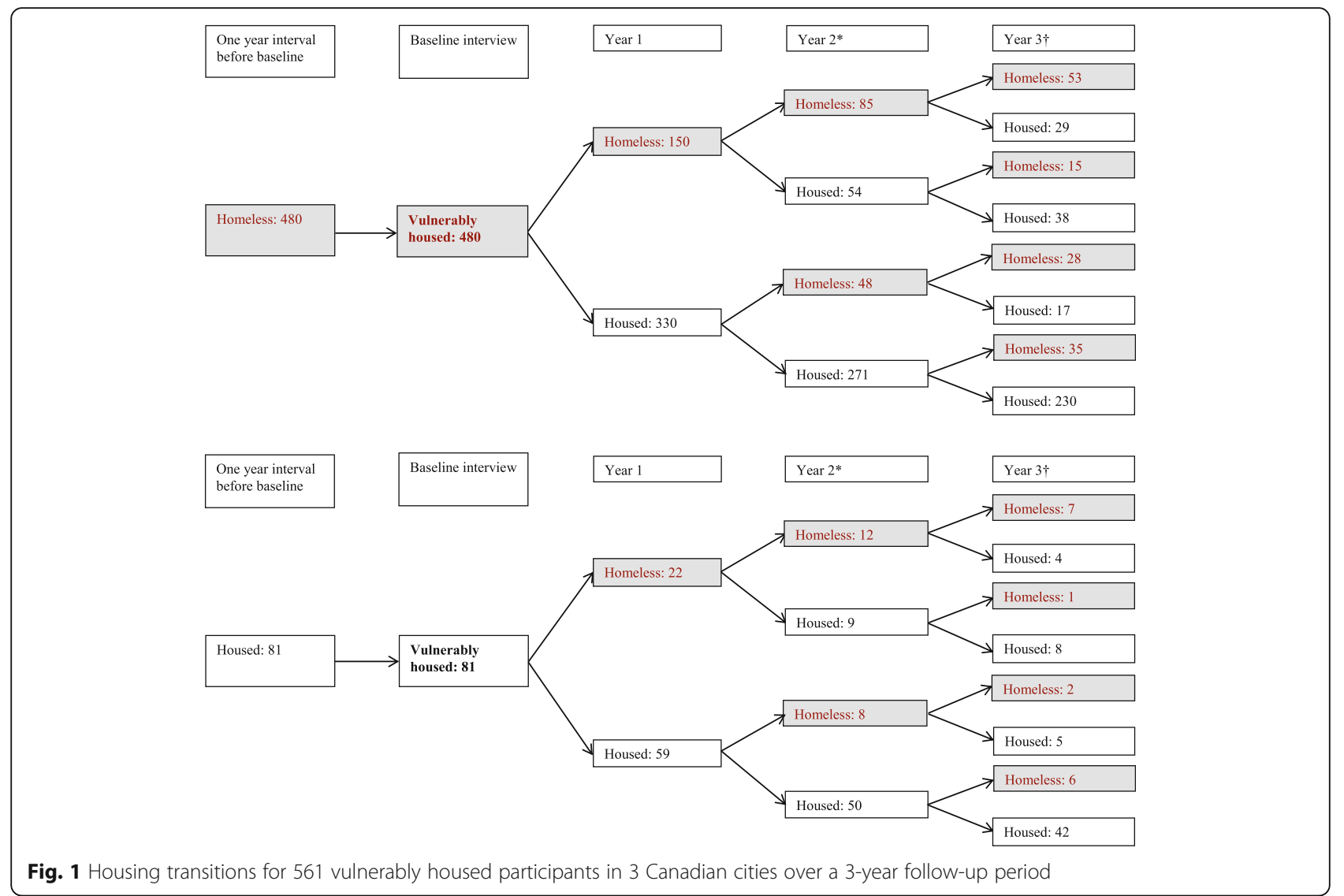

individuals living in Vancouver. The reasons for this observation are unclear, but these findings may be attributed to differences that could not be captured between participants at different study sites and the availability of housing and social services in each respective city. Similar to prior studies $[20,21]$, those who reported a higher proportion of time spent homeless before the baseline interview were also more likely to experience homelessness during the follow-up period.

Moderate to severe drug use problems were independently associated with experiencing homelessness in the follow-up period, with severe drug use problems significantly associated with the greatest likelihood of homelessness. Those who reported severe drug use problems were almost two times more likely to experience homelessness during the follow-up period compared with participants who reported no drug use. These findings are consistent with previous research that identified drug use as the greatest risk factor for housing instability [21]. Findings from the current study additionally suggest a dose-dependent relationship of drug use and homelessness, with more severe drug use problems being linked to an increased likelihood of subsequent homelessness among vulnerably housed adults.
Despite adjustment, participants who had less than a high school education, had 3 or more chronic health conditions, or reported higher housing quality were significantly less likely to experience homelessness over the follow-up period. While the association between attaining less than a high school education and decreased likelihood of homelessness was unexpected [6], it is similar to a previous study which found that high school completion was associated with recurrent homelessness among adults who had experienced prior homelessness [20]. The underlying explanation for this finding is unclear, but may in part, be due to the higher likelihood of individuals with lower education levels to have a learning disorder or experience unemployment and subsequently qualify for social assistance programs. Paradoxically, these vulnerably housed individuals may be less likely to experience homelessness while those with a high school education may be eligible for more employment opportunities, but may also be more likely to experience recurrent homelessness [20].

Vulnerably housed adults who had 3 or more chronic health conditions were less likely to experience homelessness over the follow-up period. This finding could also be attributed to the fact that individuals living with multiple chronic conditions may be more likely to be 
Table 3 Multivariable GEE logistic regression model of characteristics associated with experiencing homelessness during a 3-year follow-up period among vulnerably housed participants in 3 Canadian cities

\begin{tabular}{|c|c|c|c|}
\hline Characteristic & Core Model Adjusted Odds Ratio (95 \% Cl) & Final Model Adjusted Odds Ratio (95 \% Cl) & $P$ value \\
\hline \multicolumn{4}{|l|}{ City } \\
\hline Ottawa & $1.66(1.16-2.37)$ & $1.88(1.31-2.70)$ & $<0.001$ \\
\hline Toronto & $1.04(0.71-1.54)$ & $1.15(0.77-1.71)$ & 0.497 \\
\hline Vancouver & 1 & 1 & - \\
\hline For every year of age & $0.98(0.97-1.00)$ & $0.99(0.97-1.00)$ & 0.126 \\
\hline \multicolumn{4}{|l|}{ Gender } \\
\hline Male & $1.64(1.19-2.28)$ & $1.59(1.14-2.21)$ & 0.007 \\
\hline Female & 1 & 1 & - \\
\hline \multicolumn{4}{|l|}{ Highest level of education } \\
\hline Less than high school & $0.65(0.48-0.87)$ & $0.68(0.50-0.91)$ & 0.009 \\
\hline More than high school & 1 & 1 & - \\
\hline \multicolumn{4}{|l|}{ Chronic conditions } \\
\hline 1 & $0.66(0.38-1.15)$ & $0.63(0.35-1.11)$ & 0.110 \\
\hline 2 & $0.81(0.47-1.41)$ & $0.83(0.47-1.45)$ & 0.505 \\
\hline$\geq 3$ & $0.60(0.36-1.01)$ & $0.55(0.33-0.94)$ & 0.029 \\
\hline None & 1 & 1 & - \\
\hline Per $10 \%$ of time spent homeless prior to baseline & $1.07(1.02-1.12)$ & $1.06(1.01-1.11)$ & 0.018 \\
\hline Per interval year of follow-up & $0.96(0.85-1.08)$ & $0.96(0.85-1.09)$ & 0.515 \\
\hline Per unit housing quality & - & $0.99(0.97-1.00)$ & 0.048 \\
\hline \multicolumn{4}{|l|}{ DAST risk level } \\
\hline Low & - & $1.29(0.90-1.84)$ & 0.164 \\
\hline Moderate & - & $1.40(1.00-1.97)$ & 0.049 \\
\hline Substantial & - & $1.71(1.20-2.44)$ & 0.006 \\
\hline Severe & - & $1.98(1.22-3.20)$ & 0.003 \\
\hline No drug use & - & 1 & - \\
\hline
\end{tabular}

eligible for financial assistance programs and access to health and social services. They may also be given priority for subsidized and supportive housing because of their chronic medical conditions.

Those who reported higher housing quality were also less likely to experience homelessness over the follow-up period. This is an important finding that has not been previously reported and has implications for efforts to prevent homelessness. It appears that individuals living in higher quality housing characterized by aspects such as comfort, safety, privacy, and spaciousness were more likely to remain in that housing. Previous research suggests that housing quality concerns are common among vulnerably housed populations, with up to $85 \%$ of affordable housing properties having at least one health-related housing quality issue [34]. Our findings suggest that low housing quality may be a modifiable protective factor for homelessness. Thus, improving the quality of low-cost housing may decrease the likelihood that vulnerably housed individuals become homeless in the future.
The study has service provision and public health implications, highlighting the prevalence of homelessness among vulnerably housed individuals and the need for screening and treating modifiable risk factors among this population. Specifically, the findings highlight the importance of connecting individuals with addictions treatment to potentially reduce the risk of subsequent homelessness. The study also found that housing quality may be a protective factor against homelessness among vulnerably housed individuals, suggesting that this population may benefit from targeted efforts to improve housing quality in domains such as comfort, privacy, spaciousness, and safety which in turn, may help prevent subsequent homelessness. This can include assisting individuals to access subsidized housing and rent supplements to achieve housing stability $[9,35]$.

\section{Limitations}

The study has several limitations which may restrict the interpretation of its findings. The study sample was 
limited to single adults and the sampling strategy may not have been fully representative of the entire vulnerably housed population. Since data on demographic characteristics, health conditions, and housing were collected by self-report, accuracy may have been affected by recall and other sources of reporting bias. The study did not examine personality traits of participants which could contribute to both increased risk of substance use and likelihood of experiencing homelessness. In addition, participants who had severe drug use problems may not have completed the survey. Thus, the relationship between drug use problems and subsequent homelessness may have revealed an even stronger association.

Future studies should investigate risk factors for recurrent homelessness and examine predictors of homelessness over a longer follow-up period. In addition, interventions to prevent homelessness among vulnerably housed individuals should be explored given the potential public health implications.

\section{Conclusions}

The study followed housing trajectories of vulnerably housed adults and found that $29 \%$ of the study sample experienced homelessness over a 3-year period. The study also identified risk factors for homelessness among vulnerably housed individuals such as male gender, higher percentage of time spent homeless prior to baseline, and moderate to severe drug use problems. Protective factors included having 3 or more chronic conditions and higher housing quality. The study has important public health implications, highlighting the need for addictions treatment and efforts to improve housing quality among vulnerably housed individuals, which may help prevent subsequent experiences of homelessness in this population.

\section{Abbreviations}

AOR: Adjusted odds ratio; AUDIT: Alcohol Use Disorders Identification Test; DAST-10: 10-item Drug Abuse Screening Test; GEE: Generalized estimating equations; IQR: Interquartile range; MCS: Mental Component Summary; PCS: Physical Component Summary; SD: Standard deviation; SF-12: 12-item Short Form Health Survey; SRO: Single room occupancy; SSNI: Social Support Network Inventory; TBI: Traumatic brain injury

\section{Acknowledgements}

We would like to acknowledge the following individuals from our community partner organizations: Laura Cowan, Liz Evans, Sarah Evans, Stephanie Gee, Clare Haskel, and Erika Khandor. The authors also thank the study coordinators and interviewers in each of the three cities as well as the shelter, drop-in, and municipal and provincial staff for their assistance with participant recruitment and follow-up. The Centre for Urban Health Solutions in the Li Ka Shing Knowledge Institute at St. Michael's Hospital gratefully acknowledges the support of the Ontario Ministry of Health and Long-Term Care. The views expressed here are the views of the authors and do not necessarily reflect the views of any of the above named organizations.

\section{Funding}

Funding for the Health and Housing in Transition (HHiT) study was received from an operating grant (MOP-86765) and an Interdisciplinary Capacity Enhancement Grant on Homelessness, Housing and Health (HOA-80066) from the Canadian Institutes of Health Research. The funding body had no role in the design of the study and collection, analysis, and interpretation of data and in writing the manuscript.

\section{Availability of data and materials \\ The datasets generated and/or analysed during the current study are available from the corresponding author on reasonable request.}

\section{Authors' contributions}

MJT helped conceived of the study and its design, coordinated and participated in data collection, analysis and interpretation of the data, and drafted the manuscript. AP helped conceive of the study and its design and interpretation of the data. TA helped conceive of the study and its design and interpretation of the data. RN carried out statistical analyses and interpretation of the data. EG coordinated and participated in data collection and interpretation of the data. AG participated in interpretation of the data. RC participated in interpretation of the data. SF participated in interpretation of the data. VM carried out statistical analyses and interpretation of the data. SWH helped conceive of the study and its design, interpretation of the data, and supervised the study. All authors read, revised, and approved the final manuscript.

\section{Competing interests}

The authors declare that they have no competing interests.

\section{Ethics approval and consent to participate}

The Research Ethics Boards at the University of Ottawa; St. Michael's Hospital, Toronto; and the University of British Columbia, Vancouver approved this study. All study participants provided written informed consent.

\section{Author details}

${ }^{1}$ Centre for Urban Health Solutions, Li Ka Shing Knowledge Institute, St. Michael's Hospital, 30 Bond Street, Toronto, ON M5B 1W8, Canada. ${ }^{2}$ Centre for Health Evaluation and Outcome Sciences, Division of General Internal Medicine, University of British Columbia, Vancouver, BC, Canada. ${ }^{3}$ University of Ottawa, Ottawa, ON, Canada. ${ }^{4}$ Royal Ottawa Health Care Group, Ottawa, ON, Canada. ${ }^{5}$ Division of General Internal Medicine, Department of Medicine, University of Toronto, Toronto, ON, Canada.

Received: 10 April 2016 Accepted: 23 September 2016

Published online: 03 October 2016

\section{References}

1. The 2012 Point-in-Time Estimates of Homelessness. Annual Homelessness Assessment Report. Washington, D.C.: The U.S. Department of Housing and Urban Development; 2012. p. 2012.

2. The state of homelessness in Canada. 2013. Available at: http:// homelesshub.ca/sites/default/files/SOHC2103.pdf. Accessed 16 Jan 2016.

3. Frankish CJ, Hwang SW, Quantz D. Homelessness and health in Canada: research lessons and priorities. Can J Public Health. 2005;96 Suppl 2:S23-9.

4. Hwang SW. Homelessness and health. CMAJ. 2001;164(2):229-33.

5. Aubry T, Klodawsky F, Coulombe D. Comparing the housing trajectories of different classes within a diverse homeless population. Am J Commun Psychol. 2012;49(1-2):142-55.

6. Phinney R, Danziger S, Pollack HA, Seefeldt K. Housing instability among current and former welfare recipients. Am J Public Health. 2007;97(5):832-7.

7. Caton CL, Dominguez B, Schanzer B, Hasin DS, Shrout PE, Felix A, et al. Risk factors for long-term homelessness: findings from a longitudinal study of first-time homeless single adults. Am J Public Health. 2005;95(10):1753-9.

8. Folsom DP, Hawthorne W, Lindamer L, Gilmer T, Bailey A, Golshan S, et al. Prevalence and risk factors for homelessness and utilization of mental health services among 10,340 patients with serious mental illness in a large public mental health system. Am J Psychiatry. 2005;162(2):370-6.

9. Shinn M, Weitzman BC, Stojanovic D, Knickman JR, Jiménez L, Duchon L, et al. Predictors of homelessness among families in New York City: from shelter request to housing stability. Am J Public Health. 1998;88(11):1651-7.

10. Caton $C L$, Hasin D, Shrout PE, Opler LA, Hirshfield S, Dominguez B, et al. Risk factors for homelessness among indigent urban adults with no history of psychotic illness: a case-control study. Am J Public Health. 2000; 90(2):258-63. 
11. Washington DL, Yano EM, McGuire J, Hines V, Lee M, Gelberg L. Risk factors for homelessness among women veterans. J Health Care Poor Underserved. 2010;21(1):82-91.

12. Ran MS, Chan CL, Chen EY, Xiang MZ, Caine ED, Conwell Y. Homelessness among patients with schizophrenia in rural China: a 10-year cohort study. Acta Psychiatr Scand. 2006;114(2):118-23.

13. Shelton KH, Taylor PJ, Bonner A, van den Bree M. Risk factors for homelessness: evidence from a population-based study. Psychiatr Serv. 2009;60(4):465-72.

14. Kemp PA, Neale J, Robertson M. Homelessness among problem drug users: prevalence, risk factors and trigger events. Health Soc Care Community. 2006;14(4):319-28.

15. Edens EL, Kasprow W, Tsai J, Rosenheck RA. Association of substance use and $V A$ service-connected disability benefits with risk of homelessness among veterans. Am J Addict. 2011;20(5):412-9.

16. Odell SM, Commander MJ. Risks factors for homelessness among people with psychotic disorders. Soc Psychiatry Psychiatr Epidemiol. 2000;35(9):396-401.

17. Orwin RG, Scott CK, Arieira C. Transitions through homelessness and factors that predict them: three-year treatment outcomes. J Subst Abuse Treat. 2005;28 Suppl 1:S23-39.

18. van den Berk-Clark C, McGuire J. Elderly Homeless Veterans in Los Angeles: Chronicity and Precipitants of Homelessness. Am J Public Health. 2013; 103(Suppl 2):S232-38.

19. Hwang SW, Aubry T, Palepu A, Farrell S, Nisenbaum R, Hubley AM, et al. The health and housing in transition study: a longitudinal study of the health of homeless and vulnerably housed adults in three Canadian cities. Int J Public Health. 2011;56(6):609-23.

20. McQuistion HL, Gorroochurn P, Hsu E, Caton CL. Risk factors associated with recurrent homelessness after a first homeless episode. Community Ment Health J. 2014;50(5):505-13.

21. O'Connell MJ, Kasprow W, Rosenheck RA. Rates and risk factors for homelessness after successful housing in a sample of formerly homeless veterans. Psychiatr Serv. 2008:59(3):268-75.

22. Ardilly P, Le Blanc D. Sampling and weighting a survey of homeless persons: a French example. Survey Methodology. 2001;27(1):109-18.

23. Housing, Family and Social Statistics Division. Ethnic diversity survey questionnaire. Ottawa, ON. Statistics Canada. 2002; Available at: http:// www5.statcan.gc.ca/bsolc/olc-cel/olc-cel?catno=89M0019XCB\&lang=eng Accessed 16 Jan 2016

24. Statistics Canada. Canadian community health survey (CCHS). 2012. Available at: http://www23.statcan.gc.ca/imdb/p2SV.pl?Function= getSurvey \&SDDS=3226\&lang $=e n \& d b=i m d b \& a d m=8 \& d i s=2$. Accessed Jan 16, 2016

25. Slaughter B, Fann JR, Ehde D. Traumatic brain injury in a county jail population: prevalence, neuropsychological functioning and psychiatric disorders. Brain Inj. 2003;17(9):731-41.

26. Ware JE, Kosinski M, Keller SD. SF-12: How to score the SF-12 physical and mental health summary scales. 2nd ed. Boston (MA): The Health Institute, New England Medical Center; 1995

27. Babor TF, Higgins-Biddle JC, Saunders JB. AUDIT: the alcohol use disorders identification test: guidelines for use in primary care. Geneva: World Health Organization Department of Mental Health and Substance Dependence; 2001.

28. French MT, Roebuck MC, McGeary KA, Chitwood DD, McCoy CB. Using the drug abuse screening test (DAST-10) to analyze health services utilization and cost for substance users in a community-based setting. Substance Use Misuse. 2001;36(6):925-46.

29. Toro PA, Bellavia CW, Daeschler CV, Owens BJ, Wall DD, Passero JM, et al. Distinguishing homelessness from poverty: a comparative study. J Consult Clin Psychol. 1995;63(2):280-9.

30. Flaherty JA, Gaviria FM, Pathak DS. The measurement of social support: the Social Support Network Inventory. Compr Psychiatry. 1983;24(6):521-9.

31. Tsemberis S, McHugo G, Williams V, Hanrahan P, Stefancic A. Measuring homelessness and residential stability: the residential time-line follow-back inventory. J Community Psychol. 2007;35(1):29-42.

32. Rotnitzky A, Jewell NP. Hypothesis testing of regression parameters in semiparametric generalized linear models for cluster correlated data. Biometrika. 1990:77:485-97.

33. Shults J, Sun W, Tu X, Kim H, Amsterdam J, Hilbe JM, et al. A comparison of several approaches for choosing between working correlation structures in generalized estimating equation analysis of longitudinal binary data. Stat Med. 2009;28(18):2338-55.

34. Klein EG, Keller B, Hood N, Holtzen H. Affordable housing and health: a health impact assessment on physical inspection frequency. J Public Health Manag Pract. 2015;21(4):368-74.

35. Rog DJ, Marshall T, Dougherty RH, George P, Daniels AS, Ghose SS, et al. Permanent supportive housing: assessing the evidence. Psychiatr Serv. 2014;65(3):287-94

\section{Submit your next manuscript to BioMed Central and we will help you at every step:}

- We accept pre-submission inquiries

- Our selector tool helps you to find the most relevant journal

- We provide round the clock customer support

- Convenient online submission

- Thorough peer review

- Inclusion in PubMed and all major indexing services

- Maximum visibility for your research

Submit your manuscript at www.biomedcentral.com/submit
) Biomed Central 